J. Lake Sci. (湖泊科学), 2011, 23(2):246-250

http: //www.jlakes.org. E-mail: jlakes@niglas. ac.cn

(c) 2011 by Journal of Lake Sciences

\title{
鄱阳湖湖口水域鱼类群落结构及种类多样性”
}

\author{
胡茂林 ${ }^{1}$, 吴志强 $^{1,2 * *}$, 刘引兰 ${ }^{3}$ \\ ( 1 : 南昌大学生命科学与食品工程学院, 南昌 330031$)$ \\ (2: 桂林理工大学,桂林 541004$)$ \\ (3:南昌外国语学校,南昌 330025)
}

\begin{abstract}
摘 要: 2006 年 10 月- -2009 年 3 月对鄱阳湖湖口水域拖网、定置网和虾笼渔获鱼类进行逐月采样分析. 结果表明,该水 域至少有鱼类 50 种, 隶属于 6 目 12 科 42 属. 鱼类组成以湖泊定居性鱼类为主, 没有发现过河口洄游性鱼类. 渔获物组成 以光泽黄滪鱼、短领鲚和㛑等小型鱼类为主. 定置网渔获物平均数量和平均产量均是夏季 $>$ 秋季 $>$ 春季 $>$ 冬季. 种类丰度 及产量变化与该水域的水位和水温变化总体呈正相关关系. Shannon-Wiener 多样性指数月变化在 $1.16-2.58$ 之间,多数 月份指数值在 2 以下, 多样性水平偏低. 目前, 鄱阳湖湖口水域定置网捕捞规模较大, 渔获鱼类中经济鱼类所占比例较少, 且绝大多数个体较小, 应加强鱼类资源的管理和保护.
\end{abstract}

关键词: 鄱阳湖;湖口水域;鱼类;群落结构;种类多样性

\section{Fish diversity and community structure in Hukou area of Lake Poyang}

\author{
HU Maolin ${ }^{1}$, WU Zhiqiang ${ }^{1,2} \&$ LIU Yinlan ${ }^{3}$ \\ (1: School of Life Sciences and Food Engineering, Nanchang University, Nanchang 330031, P. R. China) \\ (2: Guilin University of Technology, Guilin 541004, P. R. China) \\ (3: Nanchang Foreign Language, Nanchang 330025 , P. R. China)
}

Abstract: The fish species diversity and community structure in Hukou area of Lake Poyang were investigated from October 2006 to March 2009. A total of 50 species was classified into 6 orders, 12 families and 42 genus. Eesis fish was dominated in the fish species, and none of migration diadromous fish. Among the composition of catches collected in Hukou area of Lake Poyang, Pelteobagrus nitidus, Hemiculter leucisculus and Coilia brachygnathus were the most abundant species. Seasonal variations of average fish amounts captured by set nets were ranked from higher to lower as follows: summer, autumn, spring and winter. Generally, the changes of species abundance and quantity were positively correlated with water level and water temperature. Shannon-Wiener index was relatively lower, ranged from 1.16 to 2.58 , and below 2 in most months. At the present time, fishing operation by set nets was very widespread in Hukou area of Lake Poyang. Commercial species had a lower proportion in catches and most of them were small individuals. Thus the management and protection of fish resources should be strengthened immediately in the area.

Keywords: Lake Poyang; Hukou area; fish species; community structure; species diversity

鄱阳湖位于长江中下游南岸, 是仅存的两个通江湖泊之一. 湖区生境复杂, 水生生物资源丰富 ${ }^{[1]}$. 湖口是 鄱阳湖唯一的人长江口, 也是洄游性鱼类在长江与鄱阳湖之间洄游的唯一通道. 20 世纪 80 年代以来, 已有一 些学者对鄱阳湖的水文 ${ }^{[1]}$ 、水质 ${ }^{[2]}$ 、污染 ${ }^{[34]}$ 、水生生物资源 ${ }^{[5-7]}$ 等进行过研究, 但对鄱阳湖湖口水域鱼类的群落 结构和种类多样性等问题尚未开展过系统的研究. 本文在 2006 年 10 月- 2009 年 3 月逐月采样的基础上,分析该水 域鱼类的群落结构及其多样性水平, 探讨湖口的水位、水温与该水域鱼类群落的关系, 并对该水域的鱼类资源及其 利用现状进行初步评价, 以期为该水域鱼类资源的合理利用和鱼类物种多样性保护提供科学依据.

* 国家自然科学基金项目 (30760188) 和南昌大学博士科研启动经费项目 (300608) 联合资助. $2010-03-30$ 收稿; 2010-06-28 收修改稿. 胡茂林,男,1981 年生,博士,讲师;E-mail:mlhu1981@ yahoo. com. cn.

** 通讯作者;E-mail: wuzhiqiang108@ hotmail. com. 


\section{1 材料与方法}

\section{1 样品来源}

鱼类样品采自鄱阳湖湖口水域的拖网、定置网和虾笼渔获物.

\section{2 采样方法}

2006 年 10 月 -2009 年 3 月对定置网和虾笼渔获鱼类进行逐月采样,每月采样一次, 收集多艘渔船的定 置网和虾笼渔获鱼类样品. 其中在 2007 年 7 月-2008 年 6 月, 采用定船定人定网的方式, 确定一艘渔船进行 定置网渔获物定量采集. 同时, 采样期间租用两艘渔船进行拖网捕捞,每个季度捕捞一次.

渔获物现场进行分类、计数、称重及生物学测定, 每种鱼类取一定数量个体进行整形固定做成标本. 将 各种鱼类标本带回实验室,依据中国淡水鱼类系统检索 ${ }^{[8]}$ 和中国动物志 ${ }^{[9-10]}$ 进行种类鉴定.

鄱阳湖湖口的水位、水温数据摘自长江水文网 (http://www. cjh. com. cn), 每天记录一次.

\section{3 生物多样性统计}

多样性分析指标包括 Margalef 种类丰富度指数 $(D)$ 、Shannon-Wiener 多样性指数 $\left(H^{\prime}\right) 、$ Simpson 优势度 指数 $(\lambda)$ 和 Pielou 均匀度指数 $(E)$, 其计算公式参考相关文献 ${ }^{[1-1-12]}$.

\section{2 结果与分析}

\section{1 鱼类群落结构及区系特征}

鄱阳湖湖口水域至少有鱼类 50 种, 隶属于 6 目 12 科 42 属 (表 1). 其中以鲤形目种类最多,有 33 种, 占 总种数的 $66.0 \%$; 鲇形目、鲇形目的种类也较多, 分别为 8 种和 6 种; 其余各目种类很少, 均只有 1 种. 科级 水平以鲤科鱼类最多,有 30 种,占总种数的 $60.0 \%$; 魭科 6 种,占 $12.0 \%$; 其次是鲉科和鮨科, 各 3 种, 分别 占 $6.0 \%$; 其余各科均只有 1 种, 分别占 $2.0 \%$.

依据鱼类的生活习性划分,该水域鱼类以湖泊定居性鱼类种数最多, 达 42 种, 占该水域鱼类总种数的 $84.0 \%$; 江湖洄游性鱼类 6 种,占 $12.0 \%$,如青鱼、草鱼、鲢、鳙、鳡和赤眼䲡等; 河流性鱼类 1 种,铜鱼; 溪流 性鱼类 1 种,胡子鲇;没有发现过河口洄游性鱼类,如鲋、刀鲚、鳗鲟等.

\section{2 鱼类种类组成的季节变化}

春季出现在鄱阳湖湖口水域的鱼类共有 20 种,其中优势种 4 种,分别为短领鲚、䱗、似鳊和光泽黄颡鱼; 夏季出现的种类最多,达 42 种,优势种只有 3 种, 为㛑、银鲖和光泽黄颖鱼; 秋季出现的鱼类共 31 种,优势种 也只有 3 种, 为短领鲚、银鲖和光泽黄颡鱼; 冬季出现的种类明显比夏、秋季减少, 共 22 种, 优势种 3 种, 为短 领鲚、餐和光泽黄滪鱼.

全年各季节均为优势的种类仅有 1 种,为光泽黄滪鱼.

\section{3 鱼类群落相对数量的季节变化}

鄱阳湖湖口水域定置网渔获鱼类年均数量为 573 尾/网, 年均产量为 $6.38 \mathrm{~kg}$ /网. 季节平均数量和平均 产量均是夏季 $>$ 秋季 $>$ 春季 $>$ 冬季. 月均数量和月均产量均以 6 月最高, 分别为 1069 尾/网和 $12.88 \mathrm{~kg} /$ 网; 1 月平均数量最低,仅为 235 尾/网; 12 月平均产量最低, 仅为 $2.28 \mathrm{~kg} /$ 网 (表 2 ).

\section{4 鱼类群落的种类多样性特征}

鄱阳湖湖口水域鱼类种类的 Margalef 丰富度指数以 6 月最高, 达到 $4.30,4$ 月最低, 为 1.71 ; ShannonWiener 多样性指数以 6.7 月较高, 分别为 2.37 和 2.58 , 9 月最低, 仅为 1.16 ; Pielou 均匀度指数也以 9 月最 低,为 0.38 ; Simpson 优势度指数则以 9 月最高, 达 0.53 (表 3 ).

\section{3 讨论}

\section{1 鄱阳湖湖口水域鱼类群落结构特征}

鄱阳湖湖口水域鱼类种类 50 种, 与整个鄱阳湖水域的 136 种 $^{[7]}$ 相比,种类明显较少. 鄱阳湖湖口水域鱼 类群落显示出以湖泊定居性鱼类和小型鱼类为主等特征 (表 1), 这一结果与以往对鄱阳湖鱼类资源的研究 结论一致 ${ }^{[7]}$. 与长江安庆江段的鱼类组成相比较, 湖口水域鱼类的种类较其丰富, 但群落结构较其简单 ${ }^{[11]}$. 
另外, 鄱阳湖湖口水域定置网渔获物组成以光泽黄颡鱼、短领鲚和㛑等小型鱼类为主, 这与 1998 年和 1999 年对鄱阳湖湖口水域定置网渔获物的调查结果相吻合 ${ }^{[7]}$.

\section{表 1 鄱阳湖湖口水域的鱼类种类名录}

Tab. 1 Fish species in Hukou area of Lake Poyang

\begin{tabular}{|c|c|c|}
\hline I 鲱形目 Clupeiformes & 18. 花䱻 Hemibarbus maculatus & 37. 胡子鲇 Clarias fuscus \\
\hline $\mathrm{i}$ 鳀科 Engraulidae & 19. 麦穗鱼 Pseudarasbora parva & vii 鲿科 Bagridae \\
\hline 1. 短领鲚 Coilia brachygnathus & 20. 华鳈 Sarcocheilichthys sinensis & 38. 黄颡鱼 Pelteobagrus fulvldraco \\
\hline II 胡瓜鱼目 Osmeriformes & 21. 小鳈 Sarcocheilichthys parvus & 39. 长须黄颞鱼 Pelteobagrus eupogon \\
\hline ii 银鱼科 Salangidae & 22. 江西鳈 Sarcocheilichthys kiangsiensis & 40. 光泽黄颡鱼 Pelteobagrus nitidus \\
\hline 2. 太湖新银鱼 Neosalanx taihuensis & 23. 黑鳍鳈 Sarcocheilichthys nigripinnis & 41. 瓦氏黄颡鱼 Pelteobagrusvachellii \\
\hline III 鲤形目 Cypriniformes & 24. 银鮈 Squalidus argentatus & 42. 圆尾拟鲿Pseudobagrus tenuis \\
\hline iii 鲤科 Cyprinidae & 25. 铜鱼 Coreius heteroden & 43. 大鳍鳠 Mystus macropterus \\
\hline 3. 青鱼 Mylopharyngodon piceus & 26. 吻鮈 Rhinogobio typus & $\mathrm{V}$ 领针鱼目 Beloniformes \\
\hline 4. 草鱼 Ctenopharyngodon idellus & 27. 棒花鱼 Abbottina rivularis & viii 鱵科 Hemirhamphidae \\
\hline 5. 赤眼鳟 Squaliobarbus curriculus & 28. 蛇鮈 Saurogobio dabryi & 44. 间下鱵 Hyporhamphus intermedius \\
\hline 6. 鳡 Elopichthys bambusa & 29. 兴凯鱊Acheilognathus chankaensis & VI 鲈形目 Perciformes \\
\hline 7. 飘鱼 Pseudolaubuca sinensis & 30. 高体鳑鲏 Rhodeus ocellatus & ix 鮨科 Serranidae \\
\hline 8. 㛑 Hemiculter leucisculus & 31. 鲤 Cyprinus carpio & 45. 鳜 Siniperca chuatsi \\
\hline 9. 贝氏㛑 Hemiculter bleekeri & 32. 鲫 Carassius auratus & 46. 斑䰻 Siniperca scherzeri \\
\hline 10. 红鳍原鲌 Culterichthys erythropterus & iv 鳅科 Cobitidae & 47. 长身鳜 Coreosiniperca roulei \\
\hline 11. 尧嘴鲌 Culter alburnus & 33. 武昌副沙鳅 Parabotia banarescui & $\mathrm{x}$ 塘鳢科 Eleotridae \\
\hline 12. 鳊 Parabramis pekinensis & 34. 中华花鳅 Cobitis sinensis & 48. 沙塘鳢 Odontobutis obscura \\
\hline 13. 鲂 Megalobrama skolkovii & 35. 泥鳅 Misgurnus anguillicaudatus & xi 鳢科 Channidae \\
\hline 14. 银鲖 Xenocypris argentea & IV 鲇形目 Siluriformes & 49. 乌鳢 Channa argus \\
\hline 15. 似鳊 Pseudobrama simoni & $\mathrm{v}$ 鲇科 Siluridae & xii 刺鳅科 Mastacembelidae \\
\hline 16. 鲢 Hypophthalmichthys molitrix & 36. 鲇 Silurus asotus & 50. 中华刺鲀 Mastacembelus sinensis \\
\hline 17. 鳙 Aristichthy nobilis & vi 胡子鲇科 Clariidae & \\
\hline
\end{tabular}

表 2 鄱阳湖湖口水域定置网渔获物鱼类 数量的季节变化

Tab. 2 Seasonal changes of fishing amount by set nets in Hukou area of Lake Poyang

\begin{tabular}{cccc}
\hline 季节 & 日期 (年-月 $)$ & $\begin{array}{c}\text { 平均数量 } \\
(\text { 尾/网 })\end{array}$ & $\begin{array}{c}\text { 平均产量 } \\
(\mathrm{kg} / \text { 网 })\end{array}$ \\
\hline 秋季 & $2007-09$ & 634 & 4.76 \\
& $2007-10$ & 739 & 8.87 \\
& $2007-11$ & 660 & 6.32 \\
冬季 & $2007-12$ & 678 & 6.65 \\
& $2008-01$ & 292 & 2.28 \\
& $2008-02$ & 538 & 3.46 \\
春季 & $2008-03$ & 454 & 6.41 \\
& $2008-04$ & 628 & 4.05 \\
& $2008-05$ & 292 & 4.18 \\
& 平均 & 455 & 7.41 \\
夏季 & $2008-06$ & 1069 & 4.92 \\
& $2007-07$ & 756 & 5.50 \\
& $2007-08$ & 584 & 6.96 \\
& 平均 & 803 & 6.05 \\
\hline
\end{tabular}

\section{2 定置网和拖网作业对鄱阳湖湖口水域鱼类群落结构 的影响}

鄱阳湖湖口水域鱼类群落虽然种类比较少, 但数量 较多、产量较高. 定置网渔获物年均为 573 尾/网和 $6.38 \mathrm{~kg} /$ 网, 产量最大的 6 月为 1069 尾/网和 12.88 $\mathrm{kg} /$ 网, 最低也有 235 尾/网 (1 月) 和 $2.28 \mathrm{~kg}$ /网 (12 月). 但渔获鱼类中小杂鱼居多, 经济种类较少, 且绝大多数个 体很小, 年平均尾重仅为 $11.13 \mathrm{~g}$, 多数没有食用价值, 只 能作为养殖鱼类和对虾的饲料. 相比较而言, 该水域拖网 作业渔获物种类更少, 但经济鱼类所占比例很大, 个体也 较大, 基本达到商品规格. 个体很小的幼鱼和经济价值不 高的小杂鱼所占比例较小, 表明定置网作业对鄱阳湖湖 口水域鱼类资源的破坏比较严重. 然而, 近年来鄱阳湖湖 口的水位偏低, 枯水季节时间延长 ${ }^{[13]}$, 使得该水域大规 模的定置网捕鱼作业. 相关部门应采取紧急措施, 加强渔 业资源的管理, 推行可持续的生态渔业模式, 促进该水域 生态环境、渔业资源的保护和恢复.

\section{3 水位、水温对鄱阳湖湖口水域鱼类群落结构的影响}

水位、水温是影响鱼类群落结构及其多样性的重要 环境因子之一 ${ }^{[12,14]}$. 鄱阳湖湖口水域渔获鱼类种数及产 
量的变化与该水域的水位和水温的变化总体呈正相关关系 (图 1), 这一结果与其它水域的研究相一 致 ${ }^{[12,14-16]}$. 但种类数及产量最高值不是出现在水位和水温最高的月份, 而是在水位、水温都处于上升期的 6 月份, 究其原因可能与鄱阳湖休渔期 (每年的 3 月 20 日至 6 月 20 日) 有关. 经过三个月的禁渔后, 该水域在 开始捕捞时 (6月底) 的渔获鱼类种数、数量及产量都有较大的增幅. 随着捕捞时间的推进和捕捞力度的加 大, 该水域的渔获鱼类种数、数量及产量均有所下降.
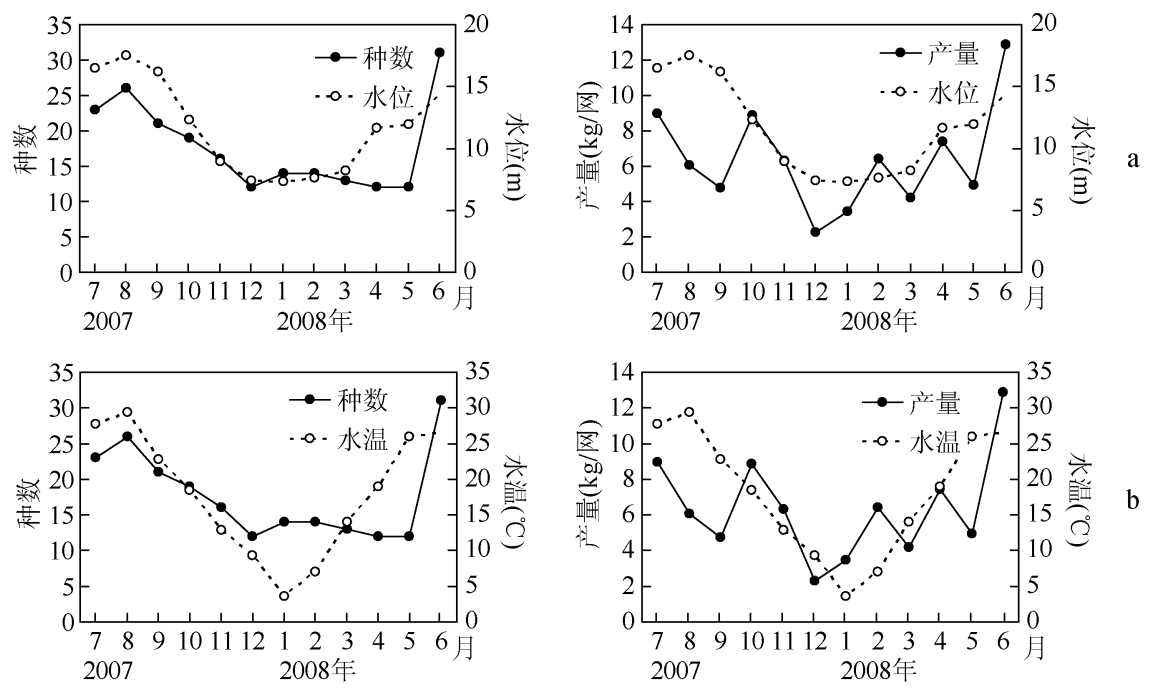

图 1 鄱阳湖湖口水域渔获鱼类种数及产量与水位 (a) 和水温 (b) 的关系

Fig. 1 Relationship between water level(a), water temperature(b) and monthly number of fish species, monthly fish yield in Hukou area of Lake Poyang

\section{4 鄱阳湖湖口水域鱼类群落的种类多样性水平}

鄱阳湖湖口水域鱼类种类多样性分析表明,目前该水域鱼类种类多样性处于较低水平,周年 12 个月的 多样性指数都低于 3 , 其中有 7 个月的指数还不到 2. 分析其原因,主要是该水域鱼类种类数较少,在周年 12 个月中有 8 个月的鱼类种类数都在 20 种以下; 且该水域鱼类各种类数量分布不均匀,其优势种的优势度突 出,造成鄱阳湖湖口水域鱼类种类多样性指数值偏低.

表 3 鄱阳湖湖口水域鱼类种类多样性

Tab. 3 Species diversities of fishes in Hukou area of Lake Poyang

\begin{tabular}{|c|c|c|c|c|c|c|c|c|c|c|c|c|}
\hline \multirow{2}{*}{ 指标 } & \multicolumn{6}{|c|}{2007 年 } & \multicolumn{6}{|c|}{2008 年 } \\
\hline & 7 月 & 8 月 & 9 月 & 10 月 & 11 月 & 12 月 & 1 月 & 2 月 & 3 月 & 4 月 & 5 月 & 6 月 \\
\hline 种类数 & 23 & 26 & 21 & 19 & 16 & 12 & 14 & 14 & 13 & 12 & 12 & 31 \\
\hline$D$ & 3.45 & 3.92 & 3.10 & 2.73 & 2.31 & 1.94 & 2.38 & 2.07 & 1.97 & 1.71 & 1.94 & 4.30 \\
\hline$H^{\prime}$ & 2.58 & 2.24 & 1.16 & 1.80 & 1.61 & 1.26 & 2.21 & 2.00 & 1.75 & 1.54 & 1.59 & 2.37 \\
\hline$E$ & 0.82 & 0.69 & 0.38 & 0.61 & 0.58 & 0.51 & 0.84 & 0.76 & 0.68 & 0.62 & 0.64 & 0.69 \\
\hline$\lambda$ & 0.09 & 0.17 & 0.53 & 0.25 & 0.28 & 0.43 & 0.14 & 0.16 & 0.22 & 0.25 & 0.25 & 0.14 \\
\hline
\end{tabular}

\section{4 参考文献}

[ 1 ] 《鄱阳湖研究》编委会. 鄱阳湖研究. 上海: 上海科学技术出版社, 1988:18-33,118.

[ 2 ] 吕兰军. 鄱阳湖水质现状及变化趋势. 湖泊科学, 1994,6 (1) :86-93.

[3] 李博之. 鄱阳湖水体污染现状与水质预测、规划研究. 长江流域资源与环境, 1996,5(1):60-66.

[ 4 ] 王毛兰, 周文斌, 胡春华. 鄱阳湖区水体氮、磷污染状况分析. 湖泊科学, 2008,20(3):334-338. 
[ 5 ] 王金秋, 吴建平, 於燕斌等. 春秋两季鄱阳湖浮游动物的编目、数量分布与变动. 湖泊科学, 2003,15(4):345-352.

[6] 胡茂林, 吴志强, 周辉明等. 鄱阳湖南矶山自然保护区渔业特点及资源现状. 长江流域资源与环境, 2005, 14 (5): 561-565.

[ 7 ] 张堂林,李钟杰. 鄱阳湖鱼类资源及渔业利用. 湖泊科学,2007,19(4):434-444.

[8] 朱松泉. 中国淡水鱼类系统检索. 南京: 江苏科学技术出版社, 1995:1-549.

[9]曹文宣,陈宜瑜,乐佩奇. 中国动物志硬骨鱼纲鲤形目 (上卷). 北京:科学出版社, 1995:1-531.

[10］褚新洛,郑葆珊,戴定远等. 中国动物志硬骨鱼纲鲇形目. 北京:科学出版社,1999:34-183.

[11] 张敏莹,徐东坡,刘 凯等. 长江安庆江段鱼类调查及物种多样性初步研究. 湖泊科学, 2006,18(6):670-676.

[12] 张雅芝,黄良敏. 厦门东海域鱼类的群落结构及种类多样性研究. 热带海洋学报,2009,28(2):66-76.

[13］胡茂林,吴志强,刘引兰. 鄱阳湖湖口水位特性及其对水环境的影响. 水生态学杂志,2010,3 (1):1-6.

[14] Sutela T, Vehanen T. Effects of water-level regulation on the nearshore fish community in boreal lakes. Hydrobiologia, 2008, 613: 13-20.

[15］王寿昆. 中国主要河流鱼类分布及其种类多样性与流域特征的关系. 生物多样性,1997,5(3):197-201.

[16] Feyrer F, Healey MP. Fish community structure and environmental correlates in the highly altered southern SacramentoSan Joaquin Delta. Environmental Biology of Fishes, 2003, 66: 123-132. 